\title{
Transplante de Células-Tronco Hematopoéticas em Doenças Reumáticas Parte 2: Experiência Brasileira e Perspectivas Futuras ${ }^{(*)}$
}

\section{Hematopoietic Stem Cell Transplantation for Rheumatic Diseases Part 2: Brazilian Experience and Future Prospectives}

\author{
Júlio C. Voltarelli( ${ }^{(1)}$, Ana Beatriz P. L. Stracieri ${ }^{(2)}$, Maria Carolina B. Oliveira ${ }^{(2,3)}$, Dannielle F. Godoi ${ }^{(3)}$, \\ Daniela A. Moraes ${ }^{(3,4)}$, Fabiano Pieroni( ${ }^{(2)}$, Kelen C. R. Malmegrim ${ }^{(4)}$, Marina A. Coutinho ${ }^{(2)}$, Belinda P. \\ Simões ${ }^{(5)}$, Celso Massumoto ${ }^{(6)}$, Nelson Hamerschlak ${ }^{(7)}$, Morton Scheinberg ${ }^{(8)}$, Eurípides Ferreira ${ }^{(9)}$, \\ Mariana Coutinho ${ }^{(10)}$, Maurício Ostronoff( ${ }^{(11)}$, Daniel Sturaro ${ }^{(12)}$, Frederico Dulley ${ }^{(13)}$
}

\section{RESUMO}

Nesta revisão, discutem-se os resultados dos transplantes de célulastronco hematopoéticas (TCTH) para doenças reumáticas graves e refratárias à terapia convencional realizados no Brasil. São analisados os resultados preliminares obtidos no Brasil com o TCTH autólogo em casos esporádicos $(\mathrm{N}=3)$ e no protocolo cooperativo iniciado em 2001 ( $N=18)$. Neste protocolo, dentre os 8 casos de nefrite lúpica, houve 3 remissões sustentadas, 3 óbitos, 1 falha de mobilização e 1 seguimento ainda muito curto; entre os 7 de esclerose sistêmica, houve 3 remissões após o TCTH e 2 após mobilização, um óbito pós-mobilização das CTH e outro após a primeira dose do condicionamento, este último em uma superposição com LES; em dois pacientes com vasculite, houve uma remissão em arterite de Takayasu e outra em doença de Behçet; uma paciente com artrite inflamatória juvenil foi incluída muito recentemente no protocolo. O seguimento dos pacientes sobreviventes variou de 0 a 48 meses, com uma mediana de 29 meses. Conclui-se com uma discussão do

\begin{abstract}
In this review, we discuss the results of hematopoietic stem cell transplantation (HSCT) for severe and refractory rheumatic diseases performed in Brazil. We analyze preliminary results obtained in Brazil with autologous HSCT in anecdotal cases $(N=3)$ and in the cooperative protocol initiated in 2001 $(N=18)$. In 8 lupus nephritis patients there were 3 sustained remissions, 3 deaths, 1 mobilisation failure and 1 short followup; in 7 systemic sclerosis patients there were 3 sustained remissions after transplantation and 2 after mobilisation, 1 death before mobilisation and another after the first dose of the conditioning in an overlapping syndrome of SLE and SSC, and between 2 patients with vasculitis there was 1 sustained remission in Takayasu's arteritis and another in Behçet's disease. One patient with juvenile idiopathic arthritis was included in the protocol very recently. The follow-up of the patients varied from 0 to 48 months with a median of 29 months. We conclude
\end{abstract}

* Trabalho realizado na Divisão de Imunologia Clínica do Departamento de Clínica Médica da Faculdade de Medicina de Ribeirão Preto da Universidade de São Paulo (FMRP-USP), Ribeirão Preto, SP, Brasil. Recebido em 01/07/2003. Aprovado, após revisão, em 29/03/2005.

1. Professor Titular e Chefe da Divisão de Imunologia Clínica do Departamento de Clínica Médica da Faculdade de Medicina de Ribeirão Preto da Universidade de São Paulo (FMRP-USP) e Coordenador da Unidade de Transplante de Medula Óssea (UTMO) do Hospital das Clínicas (HC) da FMRP-USP.

2. Médica Assistente da UTMO-HCFMRP-USP.

3. Pós-graduanda da FMRP-USP.

4. Médica bolsista da UTMO-HC-FMRP-USP.

5. Professora Doutora da Divisão de Hematologia da FMRP-USP.

6. Doutor em Medicina pela FMUSP-SP e médico assistente do Centro de Oncologia do Hospital Sírio Libanês, São Paulo, SP, Brasil.

7. Doutor em Imunologia pela USP-SP, hematologista do Programa de Oncologia e Transplante de Medula Óssea do Hospital Israelita Albert Einstein, São Paulo, SP, Brasil

8. Livre docente em Imunologia pela USP-SP, PhD pela Boston University-USA. Pesquisador associado do Hospital Israelita Albert Einstein, São Paulo, SP, Brasil.

9. Professor adjunto (aposentado) de Hematologia e Oncologia Clínica da Faculdade de Medicina da Universidade Federal do Paraná-PR e de Imunologia da UNIFESP-SP, médico hematologista do Hospital Israelita Albert Einstein, São Paulo, SP, Brasil.

10. Médica assistente do Serviço de Hematologia e Transplante de Medula Óssea. Real Hospital Português de Beneficência em Pernambuco, Recife, PE, Brasil.

11. Chefe do Serviço de Hematologia e Transplante de Medula Óssea. Real Hospital Português de Beneficência em Pernambuco, Recife, PE, Brasil.

12. Mestre em Ciências pela Faculdade de Medicina da Universidade de São Paulo (FMUSP-SP), São Paulo, SP, Brasil. Farmacêutico Chefe - Serviço de Transplante de Medula Óssea, HC-FMUSP.

13. Livre-docente em Hematologia pela FMUSP-SP e chefe do Serviço de Transplante de Medula Óssea do HCFMUSP-SP.

Endereço para correspondência: Prof. Dr. Júlio C. Voltarelli. Hemocentro Regional, Campus-USP, CEP 14051-140. Ribeirão Preto, SP, Brasil. Tel. (16) 2101-9369, fax 016-2101-9309,E-mail: jcvoltar@fmrp.usp.br

Rev Bras Reumatol, v. 45, n. 5, p. 301-12, set./out., 2005 
custo-benefício do TCTH em face das novas formas de imunossupressão disponíveis e das perspectivas futuras em países desenvolvidos, onde se iniciaram recentemente estudos prospectivos randomizados comparando o transplante com a melhor terapia medicamentosa disponível, e no Brasil, onde o custo do transplante é muito inferior ao das novas terapias biológicas.

Palavras-chave: células-tronco hematopoéticas, transplante de medula óssea, doenças reumáticas.

\section{INTRODUÇÃO}

Nos últimos nove anos, foram desenvolvidos em diversas partes do mundo vários protocolos de tratamento de doenças autoimunes (DAI) graves e refratárias com imunossupressão intensa ou imunoablação, seguida de transplante de células-tronco hematopoéticas (TCTH) autólogas ou alogênicas, baseandose em um conjunto de evidências científicas de ordem clínica e experimental, discutidas na primeira parte desta revisão ${ }^{(1)}$. No Brasil, o transplante realizado no Hospital Albert Einstein, em São Paulo, SP, com CTH não-manipuladas, em uma paciente com crioglobulinemia, anemia hemolítica e vasculite, em abril de 1996, foi um dos primeiros a serem realizados no mundo em DAI isolada, mas, infelizmente, foi relatado apenas em um evento científico nacional ${ }^{(2)}$.

A maioria dos pacientes com doenças reumáticas recebe transplante autólogo de CTH, que são mobilizadas da medula óssea para o sangue periférico com ciclofosfamida e fator de crescimento granulocitário (G-CSF), coletadas por leucocitaférese, selecionadas positivamente $\left(\mathrm{CD} 34^{+}\right) \mathrm{em}$ colunas de afinidade comerciais ou não-manipuladas e criopreservadas (em freezers mecânicos a $-85^{\circ} \mathrm{C}$ ou em nitrogênio líquido). Os regimes de condicionamento (imunossupressão pré-transplante) variaram de acordo com a doença de base, a maioria deles inclui ciclofosfamida e globulina antitimocitária (ATG - antithymocyte globulin), mas alguns grupos americanos utilizam a irradiação corporal total (TBI - total body irradiation), principalmente para esclerose sistêmica e artrite reumatóide.

Várias revisões sobre o uso de TCTH em DAI foram publicadas nos últimos anos ${ }^{(3-13)}$, inclusive analisando a experiência brasileira, isoladamente ${ }^{(14,15)}$ ou combinada com a chinesa ${ }^{(16)}$, pois o Brasil e a China são os principais países em desenvolvimento com programas de TCTH para DAI. Nesta revisão, são analisados os resultados clínicos dos TCTH para doenças reumáticas realizados no Brasil e discutidas as perspectivas futuras de evolução nessa área. Os resultados dos transplantes realizados no exterior foram discutidos na primeira parte desta revisão, publicada em número precedente desta revista ${ }^{(1)}$. the study with a discussion of future prospectives in developed countries, where randomized trials comparing transplantation with the best pharmacological therapy available have started recently, and in Brazil, where several adaptations of existing protocols are required and the cost of transplantation is much lower than that of new biological therapies.

Keywords: hematopoietic stem cells, bone marrow transplantation, rheumatic diseases.

\section{RESULTADOS PRELIMINARES NO BRASIL}

No Brasil, como mencionado acima, foi realizado um dos primeiros TCTH para DAI isolada no mundo, em abril de 1996, no Hospital Albert Einstein, SP, Brasil, em uma paciente com crioglobulinemia ${ }^{(2)}$, seguido por outro, da mesma doença, em 1999, ambos com resultados favoráveis (Tabela 1). Na Universidade Católica de Porto Alegre, RS, Brasil, também em 1999, foi transplantado um paciente com esclerose sistêmica (ES), com comprometimento cutâneo, pulmonar e digestivo, o qual recebeu condicionamento de baixa dose $\left(1,5 \mathrm{~g} / \mathrm{m}^{2}\right.$ de ciclofosfamida e $105 \mathrm{mg} / \mathrm{m}^{2}$ de fludarabina) e infusão de $2 \times 10^{6} \mathrm{CTH}$ autólogas $/ \mathrm{kg}$. Houve melhora transitória do quadro intestinal, mas, três meses após o transplante, apresentou crise hipertensiva e recrudescimento do quadro intestinal, sendo, então, repetido o esquema imunossupressor do condicionamento (3 e 5 meses póstransplante). Entretanto, um ano após o transplante, ocorreu obstrução intestinal, provavelmente por recidiva da doença de base, pneumonia aspirativa e óbito ${ }^{(17)}$ (Tabela 2).

Em um workshop internacional realizado em Ribeirão Preto, SP, Brasil, em outubro de 2000, com a presença de especialistas em TMO da Europa, dos EUA e dos principais grupos do país, ao lado de especialistas em DAI, decidiu-se iniciar um projeto piloto (de fases I/II) de TCTH para DAI, cooperativo de âmbito nacional, coordenado pelo Centro de Terapia Celular do Hemocentro de Ribeirão Preto e pela Unidade de TMO do Hospital das Clínicas da FMRPUSP. Os transplantes foram iniciados em junho de 2001, primeiramente em formas graves de lúpus eritematoso sistêmico (LES), ES e esclerose múltipla refratárias à terapia convencional, empregando CTH autólogas não-manipuladas, com depleção in vivo de células $\mathrm{T}$ com globulina antitimocitária (ATG). O protocolo está se estendendo para outras DAI e, mesmo, para doenças inflamatórias de etiopatogenia indeterminada (vide abaixo). Até setembro de 2005, foram transplantados 40 pacientes com esclerose múltipla, 9 pacientes com diabetes melito do tipo I, 3 pacientes com esclerose lateral amiotrófica, 2 pacientes com pênfigo e foram incluídos no estudo 18 pacientes afetados 
por doenças reumáticas, cuja evolução será discutida a seguir, separada em doenças específicas (Tabela 1).

\section{LÚPUS ERITEMATOSO SISTÊMICO}

Os oito pacientes com LES incluídos no protocolo de TCTH eram portadores de glomerulonefrite refratária à imunossupressão com pulsos de ciclofofamida endovenosa e outras drogas (Tabela 2). Dois pacientes não chegaram a receber a infusão de CTH, o primeiro (n. ${ }^{\circ} 5$ - Tabela 1) foi a óbito dois dias antes da infusão programada (D-2) por insuficiência renal aguda e septicemia e no segundo (n. $\left.{ }^{\circ} 7\right)$, acometido de obesidade mórbida, não se conseguiu coletar o número suficiente de CTH em quatro tentativas. Neste paciente, houve reativação da nefrite lúpica após as tentativas de mobilização, reiniciando-se a imunossupressão.
Dos seis pacientes submetidos ao TCTH, cinco deles (n. ${ }^{\text {os }}$ 1, 2, 3, 6 e 8) apresentaram insuficiência renal aguda concomitante ao regime de condicionamento com ciclofosfamida e ATG e dois deles (n. ${ }^{\text {ss }} 2$ e 6 ) foram a óbito em conseqüência desta complicação associada à septicemia. Dos quatro pacientes sobreviventes, dois (n. ${ }^{\text {os }} 1$ e 4 ) estão em remissão da nefrite depois de 48 e 38 meses do transplante, respectivamente, sem uso de qualquer imunossupressão. O primeiro desses pacientes apresentava síndrome nefrótica secundária à nefrite lúpica proliferativa difusa e obteve remissão clínica e laboratorial após o transplante, sustentada por 48 meses (Figura 1). Um outro paciente (n. ${ }^{\circ}$ ) permaneceu em remissão durante dois anos, sofreu infarto agudo do miocárdio, seguindo-se piora da função renal, não respondeu a pulso de metilprednisolona e deverá reiniciar imunossupressão.
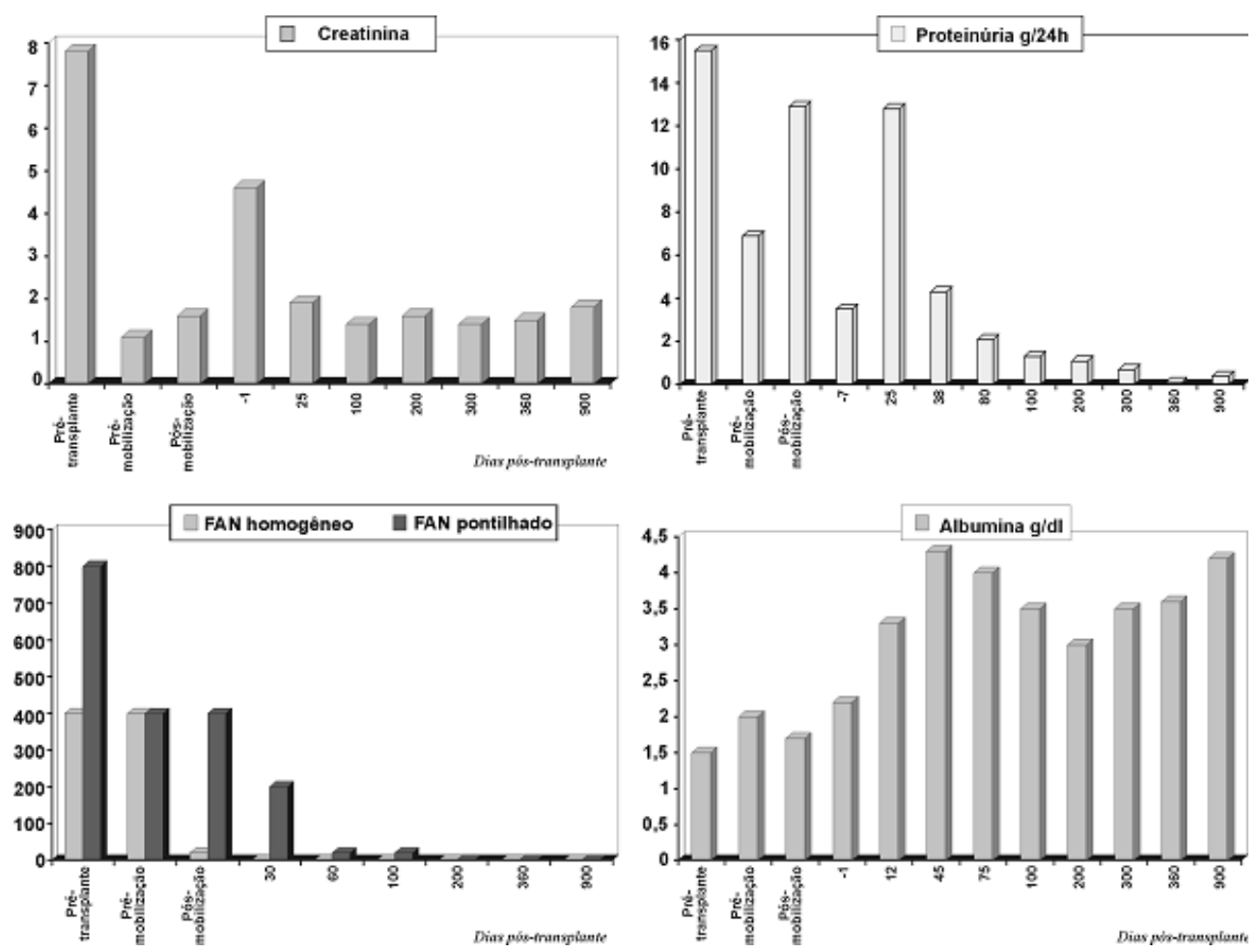

FIGURA 1 - Evolução laboratorial do primeiro paciente com lúpus eritematoso sistêmico que recebeu transplante de células-tronco hematopoéticas (TCTH) no Brasil. É um homem de 26 anos de idade, que se apresentou na Divisão de Nefrologia do HCFMRP-USP em outubro de 2000 com síndrome nefrótica, diagnosticada como glomerulonefrite lúpica classe IV por biópsia renal (índice de atividade 12/24 e de cronicidade 0/24). Desenvolveu insuficiência renal aguda em seguida ao primeiro pulso de ciclofosfamida, regredindo com hemodiálise. Após sete pulsos de ciclofosfamida, persistia com proteinúria entre 3,5 e 7,0 g/24 h e anticorpo anti-DNA nativo positivo, sendo, então encaminhado para TCTH. Este foi realizado em setembro de 2001, apresentando algumas complicações (insuficiência renal, anasarca, tamponamento cardíaco, cistite hemorrágica e bacteremia) que foram tratados com sucesso. Após a alta hospitalar, que ocorreu no D+30, houve melhora progressiva das manifestações clínico-laboratoriais e o paciente encontra-se, atualmente, 48 meses após o transplante, sem usar qualquer medicação. (Descrição e análise mais detalhadas dos quatro primeiros casos transplantados para nefrite lúpica pode ser encontrada na referência 22) 


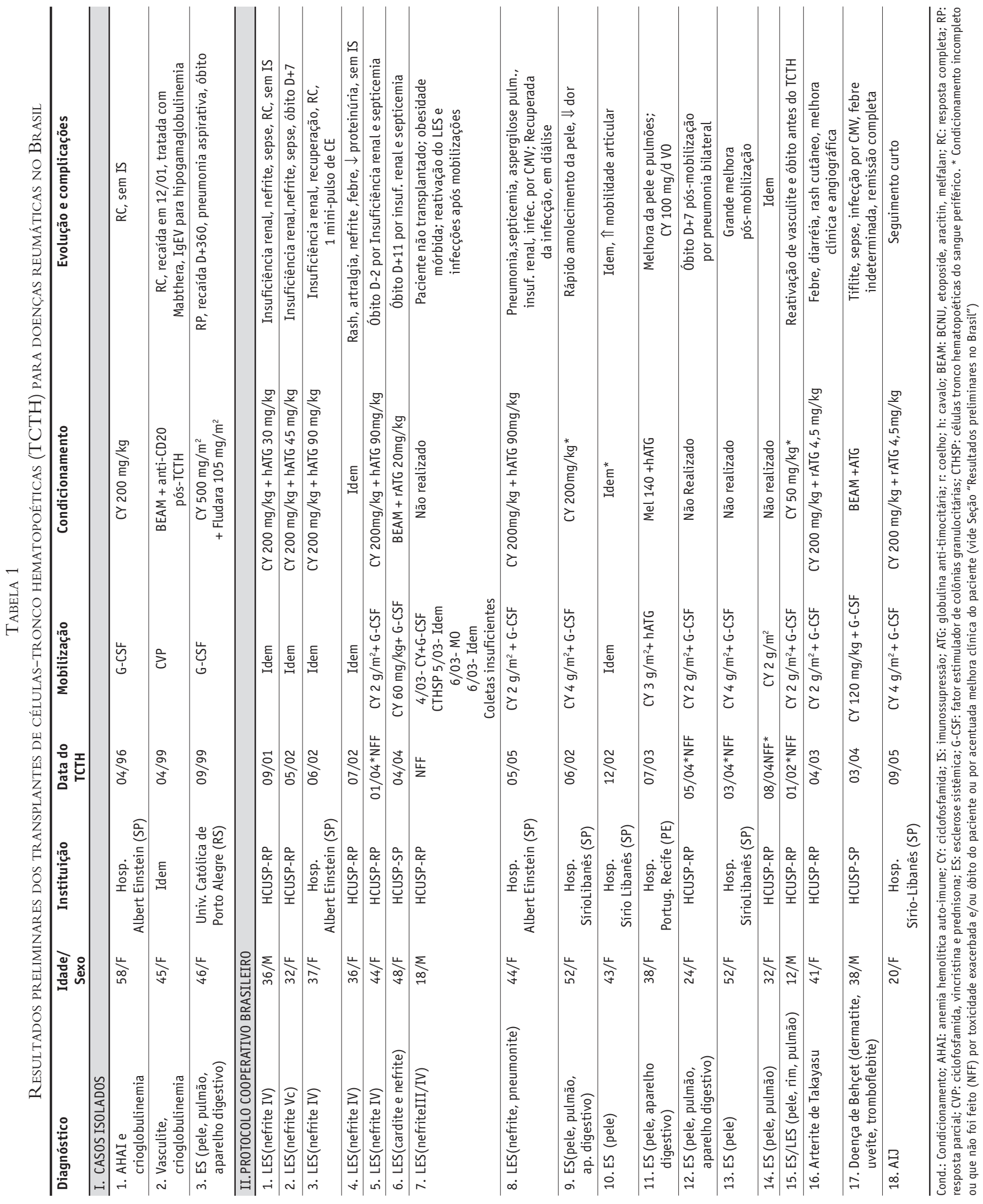




\section{ESCLEROSE SISTÊMICA}

Dos sete pacientes com esclerose sistêmica incluídos no protocolo, quatro deles não chegaram a ser transplantados, dois foram a óbito antes do transplante, por reativação da doença (Paciente n. ${ }^{\circ}$ 15, Tabela 1) ou por complicações infecciosas pós-mobilização (n. $\left.{ }^{\circ} 12\right)$ e dois pacientes obtiveram importante melhora das lesões cutâneas após a mobilização com ciclofosfamida mais G-CSF, optando por não prosseguir para o condicionamento e transplante (n. ${ }^{\text {os }}$ 13 e 14). Os três pacientes transplantados (n. ${ }^{\text {os }} 9,10$ e 11) obtiveram marcante e rápida melhora do quadro cutâneo, que se mantém após 26 a 39 meses de tratamento. Apenas o paciente n. ${ }^{\circ} 11$ persiste em uso de imunossupressão em dose baixa (ciclofosfamida $100 \mathrm{mg}$ /dia VO) para manutenção da função pulmonar, que permanece estável após 26 meses de seguimento.

\section{VASCULITES}

O transplante realizado para arterite de Takayasu foi o primeiro da literatura para vasculite de grandes vasos (Caso n. ${ }^{\circ}$ 16, Tabela 1$)^{(18)}$. A paciente apresentava obstruções arteriais múltiplas, inclusive carotídea, agravando-se progressivamente apesar de receber várias formas de imunossupressão (ciclofosfamida, metotrexato, micofenolato de mofetil e clorambucil). Recebeu condicionamento com ciclofosfamida e ATG de coelho e teve alta sem complicações significativas, apresentando significativa melhora sintomática e angiográfica já dois meses após o transplante, estado que se mantém no seguimento de 29 meses (Figura 2). A rápida reparação das lesões vasculares após o TCTH, neste caso, sugere, além do efeito antiinflamatório da imunossupressão maciça, a possível indução de neoangiogênese pelas $\mathrm{CTH}$, a exemplo do que parece ocorrer na esclerose sistêmica ${ }^{(19)}$.

Um outro transplante, para doença de Behçet, realizado no HCSP-USP, apesar de cursar com várias complicações infecciosas, que foram revertidas, resultou em remissão completa do quadro clínico, após 18 meses de seguimento.

Esta experiência de quatro casos de vasculite sistêmica grave obtendo remissão completa após o transplante (Tabela 1), incluindo dois que antecedem o protocolo cooperativo nacional, compara-se favoravelmente com as maiores casuísticas internacionais, como a relatada pelo grupo de Heidelberg em 2004, com cinco casos, em que apenas dois obtiveram remissão completa ${ }^{(20)}$.

\section{ARTRITE IDIOPÁTICA JUVENIL}

Uma paciente feminina de 20 anos de idade, com uma forma gravemente progressiva de AIJ, refratária a várias drogas imunossupressoras, incluindo agentes biológicos como os anti-TNF, foi incluída recentemente no protocolo de TCTH no Hospital Sírio Libanês, SP, devendo ser submetida à mobilização das CTH em breve.

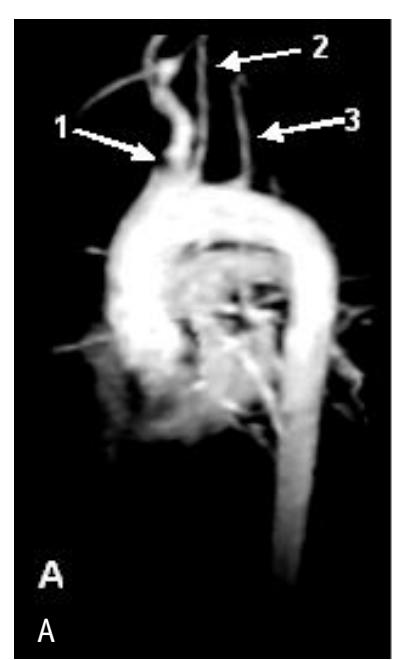

Pré-TCTH

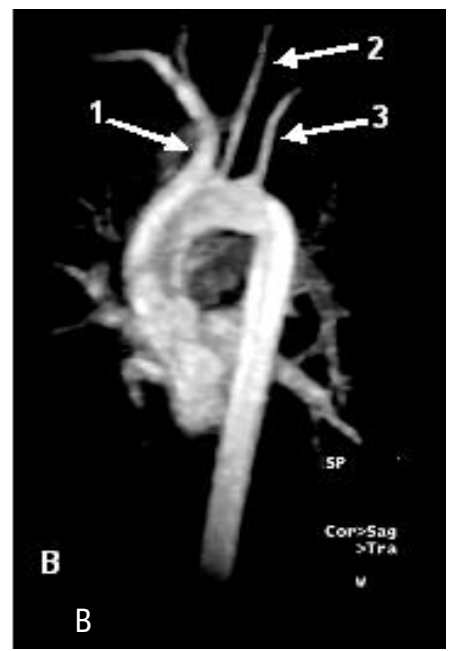

D+60 pós-TCTH

Figura 2 - Angiorressonância magnética do tronco braquicefálico da paciente com arterite de Takayasu submetida a transplante de células-tronco hematopoéticas (TCTH) autólogo. As imagens obtidas mostram correção da estenose da artéria braquiocefálica (seta 1) e redução das irregularidades da artéria carótida esquerda (seta 2) e da artéria subclávia esquerda (seta 3). (Adaptada da referência 18) 


\section{ANÁlise dos RESULTADOS}

A experiência brasileira global foi relatada na literatura nacional $^{(14,15)}$ e internacional ${ }^{(16)}$ e atualizada recentemente no congresso europeu de $\mathrm{TMO}^{(21)}$, enquanto a experiência com os quatro primeiros casos de nefrite lúpica foi apresentada na literatura nefrológica nacional ${ }^{(22)}$. Nesses trabalhos e nos subseqüentes em preparação, são analisados detalhadamente os aspectos de significativa morbimortalidade inicial do procedimento, traduzidos, por exemplo, por insuficiência renal aguda após a mobilização e/ou após o início do condicionamento, o que ocorreu em 6 dos 8 pacientes com LES, ocasionando o óbito de 3 deles (n. ${ }^{\text {s }} 2$, 5 e 6), tendo 2 pacientes (n. ${ }^{\text {os }} 1$ e 3 , Tabela 1 ) se recuperado com tratamento de suporte e hemodiálise e um outro paciente (n. ${ }^{\circ}$ ) estando em recuperação. No paciente com a síndrome de superposição (LES + ES, n. $\left.{ }^{\circ} 15\right)$, houve suspeita inicial de toxicidade cardíaca pela ciclofosfamida, mas, similarmente a um caso relatado na literatura ${ }^{(23)}$, os dados clínicos e anátomo-patológicos demonstraram a exacerbação da doença de base, produzindo vasculite pulmonar e cerebral, como causa do óbito, que ocorreu após a primeira dose de ciclofosfamida. O outro óbito de nossa casuística ocorreu em uma paciente (n. ${ }^{\circ} 12$ ) com ES difusa rapidamente progressiva, que apresentou septicemia em seguida à mobilização das CTH e antes da realização do transplante.

As complicações clínicas pós-transplante, igualmente encontradas em centros internacionais, serão, certamente, reduzidas com a maior experiência das equipes em manejálos ("curva de aprendizagem"), como ocorreu em outros centros $^{(3-13)}$. Entretanto, mesmo com os maiores avanços neste manejo, a morbimortalidade relacionada ao transplante não poderá ser completamente eliminada ou trazida a níveis ínfimos em uma população de pacientes com comprometimento sistêmico grave, refratários à imunossupressão convencional, e que recebe imunossupressão em altas doses. Isso só poderá ser conseguido quando os estudos prospectivos randomizados (de fase III), atualmente em andamento na Europa e se iniciando nos EUA, combinados com os progressos na estratificação prognóstica das DAI, permitirem o uso do TCTH em fases mais precoces dessas doenças. Para os pacientes de alto risco, como os atualmente selecionados para transplante, outra estratégia é resgatar uma parte deles com terapias inovadoras, como agentes anticitocinas, anticorpos monoclonais ou novos imunossupressores $^{(24)}$, que acarretam menor morbimortalidade do que a imunossupressão agressiva do transplante. Entretanto, mesmo nesta nossa experiência preliminar, com um grupo de pacientes de alto risco e refratários à melhor terapia imunossupressora disponível, a maioria dos pacientes (10/ 17) melhorou significativamente e teve a progressão da sua doença interrompida, sem o uso de imunossupressão após o transplante ou a mobilização, ilustrando o enorme potencial remissivo desta terapia.

Este projeto está se expandindo e deverá evoluir para o tratamento de outras DAI em que o TCTH já foi testado, como a artrite reumatóide e variantes, polineuropatias desmielinizantes, miastenia gravis, pênfigos e a doença de Crohn, e de DAI em que o TCTH ainda não foi testado, como o diabetes melito do tipo $\mathrm{I}^{(25)}$, ao lado de doenças inflamatórias imunológicas de péssimo prognóstico, como a asma brônquica potencialmente fatal, fibrose pulmonar primária $^{(26)}$ e a esclerose lateral amiotrófica ${ }^{(27)}$.

Após esta fase piloto de recrutamento de centros participantes e de aquisição de experiência no manejo dos problemas particulares de pacientes com DAI submetidos a TCTH, planeja-se o desenvolvimento de protocolos randomizados de fase III. Estes estudos terão de ser selecionados para responder questões relevantes para os pacientes de nosso meio, além da comparação entre o transplante e a terapia medicamentosa otimizada, tais como: 1) importância da manipulação in vitro do enxerto; 2) da imunossupressão pós-transplante e de transplantes alogênicos subablativos para evitar recaídas; 3) de regimes de condicionamento mais brandos para diminuir a morbimortalidade do procedimento; e 4) o papel da própria infusão das células-tronco após a imunoablação induzida por quimioterapia e imunoterapia em altas doses (vide a seguir). Provavelmente, o primeiro desses estudos de fase III não será realizado no campo das doenças reumáticas, mas em doenças neurológicas, como a esclerose múltipla, em que a experiência com o TCTH é mais ampla e a mudança do regime de imunossupressão (de BEAM + ATG para ciclofosfamida + ATG) reduziu significativamente a morbimortalidade do procedimento.

\section{QUESTÕES PENDENTES E PERSPECTIVAS FUTURAS}

A experiência clínica internacional acumulada até agora em TCTH para DAI ${ }^{(1,3-13)}$ mostrou apenas a potencialidade da terapia, mas não respondeu ainda inúmeras questões importantes relacionadas a ela (Tabela 2): 1) qual é o mecanismo da ação terapêutica do transplante autólogo nas DAI, particularmente, o papel das CTH infundidas?; 2) quais são os melhores esquemas de mobilização das CTH e de condicionamento para cada doença?; 3) a depleção in vivo 
ou in vitro de linfócitos do enxerto é necessária para a ação terapêutica?; 4) quais são as adaptações que devem ser feitas em países em desenvolvimento para a implantação de programas de TCTH para doenças reumáticas?; 5) o transplante autólogo de CTH é mais eficiente que a terapêutica convencional otimizada e é suficiente para induzir cura/remissão prolongada de doenças reumáticas ou serão necessários outros tipos de transplante (alogênico mieloablativo ou subablativo)?; e, finalmente, 6) a toxicidade do transplante estará dentro de limites aceitáveis, propiciando uma relação risco-benefício que recomende o encaminhamento de pacientes pelos especialistas?

Essas duas últimas questões (n. ${ }^{\text {os }} 5$ e 6 ) merecem atenção especial e têm sido intensamente debatidas na literatura internacional ${ }^{(28-32)}$, uma vez que estão diretamente relacionadas à decisão de encaminhamento de pacientes pelos especialistas responsáveis pelo tratamento convencional das DAI. Pela experiência acumulada até agora, sabe-se que a morbimortalidade do TCTH autólogo para DAI é, em geral, superior à observada nos transplantes para doenças oncohematológicas e varia de acordo com a enfermidade (maior na ES, LES e ARJ do que na AR do adulto e na EM). Esta diferença pode ser explicada pela seleção dos pacientes, que geralmente são transplantados em fase avançada, com comprometimento de órgãos vitais pela doença básica ou por terapia prévia e pelas características dos transplantes, em que a depleção de linfócitos T e B empregada na maioria dos protocolos aumenta consideravelmente as complicações infecciosas $^{(33-34)}$ e predispõe a doenças linfoproliferativas ${ }^{(35)}$. Em decorrência dessa toxicidade particular do TCTH, particularmente para algumas DAI, como o LES e a ES, há uma tendência em se esgotar as alternativas terapêuticas de imunossupressão, empregando anticorpos monoclonais antiTNF, anti-CD20 (rituximabe), anti-CD52 (CAMPATH), micofenolato de mofetil e outras abordagens inovadoras ${ }^{(24)}$, antes de se indicar o TCTH em pacientes de alto risco.

Entretanto, com o aperfeiçoamento dos critérios de seleção, evitando a inclusão de pacientes com lesões irreversíveis, e do manejo das complicações específicas, a toxicidade do TCTH tem diminuído nos últimos anos e se aproximado daquela observada em doenças onco-hematológicas (mortalidade em torno de $5 \%)^{(3-13)}$. Os resultados dessa "curva de aprendizagem" deverão ficar mais nítidos nos estudos randomizados recém-iniciados na Europa e EUA, os quais revelarão a morbimortalidade do procedimento em sua fase mais madura e, principalmente, sua eficácia comparada ao melhor tratamento convencional disponível. De posse dessas informações, os especialistas

TABELA 2

QueSTÕES CIENTÍFICAS PENDENTES SOBRE O TRANSPLANTE DE CÉLULAS-TRONCO HEMATOPOÉTICAS (TCTH) EM DOENÇAS AUTO-IMUNES

\begin{tabular}{|c|c|c|c|}
\hline Questão & Possiveis respostas & Estratégias de investigação & Referência \\
\hline $\begin{array}{l}\text { 1) Qual é o papel das CTH } \\
\text { na resposta terapêutica? }\end{array}$ & $\begin{array}{l}\text { CTH podem produzir tolerância, } \\
\text { reparo tecidual ou apenas acelerar } \\
\text { reconstituição imune pós-imunoablação }\end{array}$ & $\begin{array}{l}\text { Estudo randomizado de IS maciça com } \\
\text { vs. sem CTH ou marcação das } \\
\text { CTH infundidas com vírus }\end{array}$ & $46-62$ \\
\hline $\begin{array}{l}\text { 2) Quais são os melhores } \\
\text { esquemas de mobilização } \\
\text { e condicionamento? }\end{array}$ & $\begin{array}{l}\text { Esquemas específicos para cada } \\
\text { doença ou comuns para várias } \\
\text { doenças (CY/ATG ou CY/TBI/ATG) }\end{array}$ & $\begin{array}{c}\text { Estudos randomizados comparando } \\
\text { esquemas, o que não está } \\
\text { sendo realizado }\end{array}$ & $11,63-67$ \\
\hline $\begin{array}{l}\text { 3) Manipulação in vitro ou } \\
\text { in vivo do enxerto é necessária } \\
\text { para o efeito terapêutico? }\end{array}$ & $\begin{array}{l}\text { Reinfusão de linfócitos } \\
\text { auto-reativos pode ou não causar } \\
\text { reemergência da auto-imunidade }\end{array}$ & $\begin{array}{c}\text { Estudos randomizados comparando } \\
\text { estratégias de manipulação } \\
\text { vs. não-manipulação }\end{array}$ & 68 \\
\hline $\begin{array}{l}\text { 4) Que adaptações serão } \\
\text { necessárias nos países em } \\
\text { desenvolvimento para o uso } \\
\text { do TCTH em DAI? }\end{array}$ & $\begin{array}{c}\text { Adotar os mesmos procedimentos } \\
\text { dos países desenvolvidos e engajar-se } \\
\text { em seus protocolos randomizados } \\
\text { ou criar os próprios }\end{array}$ & $\begin{array}{c}\text { Estudos clínicos e randomizações } \\
\text { dirigidas às doenças e questões } \\
\text { mais importantes dos países } \\
\text { subdesenvolvidos }\end{array}$ & $14-16$ \\
\hline $\begin{array}{l}\text { 5) } 0 \text { TCTH autólogo será } \\
\text { suficiente para induzir cura } \\
\text { ou remissão longa da DAI? }\end{array}$ & $\begin{array}{l}\text { Relação custo/benefício do TCTH } \\
\text { autólogo poderá ou não ser vantajosa } \\
\text { em relação à terapia convencional } \\
\text { e ao transplante alogênico }\end{array}$ & $\begin{array}{c}\text { Estudos randomizados de TCTH autólogo } \\
\text { vs. terapia convencional (em andamento) } \\
\text { ou vs. alogênico (no futuro) }\end{array}$ & $1,3-13$ \\
\hline $\begin{array}{l}\text { 6) A toxicidade do TCTH } \\
\text { justificará o encaminhamento } \\
\text { dos pacientes para transplante? }\end{array}$ & $\begin{array}{l}\text { Mortalidade do TCTH autólogo pode } \\
\text { ser reduzida }(<5 \%) \text { ou se manter } \\
\text { alta por condições específicas do } \\
\text { paciente ou do transplante }\end{array}$ & $\begin{array}{l}\text { "Curva de aprendizagem" do manejo } \\
\text { de complicações e melhor } \\
\text { seleção de pacientes }\end{array}$ & $28-37$ \\
\hline
\end{tabular}


que cuidam dos pacientes com DAI graves, em conjunto com os próprios pacientes, poderão tomar uma decisão bem fundamentada sobre a melhor alternativa terapêutica a ser seguida. Antes disso, a decisão é ainda baseada largamente na visão subjetiva e nas preferências do especialista e do paciente, o qual, muitas vezes, toma a iniciativa de procurar o transplante em razão do grande sofrimento infligido pela sua doença e pelas complicações do tratamento convencional.

As considerações acima são particularmente relevantes no grupo pediátrico, onde os efeitos mórbidos, tanto da doença reumática grave como da cito-redução agressiva, tendem a ser potencializados pelo desenvolvimento somático-puberal. Assim, um grupo de trabalho reunido recentemente pelo NIH discutiu esses aspectos, apontando critérios de inclusão e exclusão no TCTH e de escolha da melhor terapia convencional para futuros protocolos randomizados envolvendo as principais doenças reumáticas pediátricas (AIJ, esclerose sistêmica, dermatopolimiosite juvenil e lúpus eritematoso sistêmico) ${ }^{(36)}$. $\mathrm{Na}$ AIJ seriam incluídas crianças com pelo menos um ano de doença com atividade inflamatória, no mínimo em cinco articulações, nos últimos seis meses, apesar de tratamento agressivo ou com toxicidade inaceitável dos medicamentos convencionais. No LES, as síndromes que justificariam a indicação do TCTH seriam glomerulonefrite classe IV, neuropatia central, citopenias hematológicas, incluindo a púrpura trombocitopênica trombótica, pneumonite, mielite transversa e síndrome antifosfolípide sintomática. Já na ES e na DPM juvenil, o TCTH seria indicado na presença de doença pulmonar progressiva ou comprometimento cutâneo ou muscular grave e progressivo, a despeito de terapia medicamentosa otimizada.

Outro fator importante a ser considerado na indicação do TCTH para DAI graves e refratárias é o custo do procedimento, comparado ao das terapias convencionais mais modernas. Nos Estados Unidos, onde o cuidado médico estimado a um paciente com AR varia de 60 a 120 mil dólares americanos por toda a vida, o custo do TCTH autólogo (em torno de 60.000 dólares por procedimento) já se mostra vantajoso ${ }^{(37)}$. Em nosso país, esta relação é ainda mais favorável na direção do transplante autólogo, remunerado, embora deficitariamente, pelo SUS em cerca de R\$14.000,00, que corresponde a alguns poucos meses de tratamento, por exemplo, com agentes anti-TNF para AR ou interferon-beta para esclerose múltipla. Além disso, especialmente para populações pobres, mas não só para elas, a descontinuidade da imunossupressão crônica, proporcionada pelo TCTH bem sucedido, representa um benefício que não pode ser medido apenas monetariamente. Por esta razão, além do Brasil ${ }^{(14-18,21-22)}$ e da China ${ }^{(16,38-40)}$, incluindo Hong-Kong ${ }^{(41)}$, outros países emergentes, como a Rússia ${ }^{(42)}$, a Hungria ${ }^{(43)}$, a Coréia do $\mathrm{Sul}^{(44)}$, a República Tcheca ${ }^{(45)}$ e a Grécia ${ }^{(46)}$ têm se dedicado crescentemente ao TCTH em DAI.

Uma outra questão de grande importância nesta área, e ainda bastante controversa, se refere ao mecanismo de ação do transplante das células-tronco hematopoéticas nas DAI e o papel das CTH (n. ${ }^{\circ}$, Tabela 2). No transplante autólogo, existem três explicações possíveis para este mecanismo de ação ${ }^{(47)}:$ 1) efeito isolado da imunossupressão em altas doses na eliminação de linfócitos auto-reativos; neste caso, as $\mathrm{CTH}$ deveriam apenas prover suporte hematopoético após a imunossupressão em altas doses, reduzindo o período de pancitopenia pós-transplante; 2) as CTH poderiam restaurar a auto-tolerância a tecidos próprios, perdida na emergência DAI; ou 3) as CTH poderiam promover reparação tecidual por meio de transdiferenciação das CTH ou outras CT em células do tecido lesado pela DAI.

A primeira hipótese é suportada pelo benefício clínico observado em pacientes submetidos a imunossupressão em altas doses $(200 \mathrm{mg} / \mathrm{kg}$ de ciclofosfamida endovenosa) sem resgate com $\mathrm{CTH}^{(48-50)}$. Nesses pacientes, o tempo de pancitopenia foi superior ao observado quando se usa resgate de CTH (14-17 dias vs. 8-10 dias) e não ocorreram recaídas após um seguimento médio de 29 meses para LES, 15 meses para anemia hemolítica auto-imune e de 6 meses a 6 anos para miastenia gravis. Entretanto, esta experiência não foi reproduzida exceto em um número limitado de pacientes tratados, em sua maioria, na Universidade Johns Hopkins, nos EUA, e não há relatos da qualidade da imunorreconstituição após o tratamento imunossupressor. Já a hipótese de reindução da tolerância imunológica pela linfoblação e infusão de CTH poderia ser comprovada por estudos de reconstituição imunológica se for demonstrada a emergência de um sistema imunológico auto-tolerante após o transplante. Vários trabalhos têm mostrado, em proporção variável, redução de auto-anticorpos e do número de células $\mathrm{T}$ auxiliares $\left(\mathrm{CD}^{+}\right)$circulantes e tissulares, correção do perfil de citocinas e da diversidade do receptor de células $\mathrm{T}$ no lúpus eritematoso sistêmico ${ }^{(51)}$, artrite reumatóide ${ }^{(52,53)}$, artrite idiopática juvenil ${ }^{(54)}$ e esclerose múltipla ${ }^{(46)}$ após TCTH autólogo. Um estudo recente correlacionou o retardo na imunorreconstituição de linfócitos T pós-TCTH na AR com deficiência de IL- $7^{(55)}$. Entretanto, apenas muito recentemente têm surgido estudos mostrando a emergência de 
células $\mathrm{T}$ virgens, recém-produzidas pelo timo, dois anos após o transplante, associada à diminuição das células $\mathrm{T}$ de memória, que seria indicativo da reprogramação do sistema imune a partir das CTH infundidas ${ }^{(56-58)}$. Finalmente, a contribuição das CTH para regeneração tecidual teria de ser testada pela marcação das células-tronco injetadas e a demonstração de sua diferenciação em tecidos dos órgãos afetados ${ }^{(59)}$. Entretanto, os marcadores celulares mais eficientes conhecidos, retrovirais, dificilmente terão seu uso permitido a curto prazo, em razão de recentes acidentes ocorridos em protocolos de terapia gênica ${ }^{(60)}$. Uma forma indireta e mais limitada de se estudar o efeito das células-tronco hematopoéticas na terapia das DAI seria por meio de protocolos randomizados comparando o TCTH com a imunossupressão em altas doses isoladas, sem infusão de $\mathrm{CTH}^{(48-50)}$. Esses estudos, entretanto, são difíceis de realizar em razão do período prolongado de neutropenia a que seria submetido o grupo controle (sem resgate hematopoético).

No transplante alogênico de CTH para DAI, além dos mecanismos aventados acima, poderia haver contribuição do efeito "enxerto-contra-autoimunidade" (células T do doador eliminando clones auto-reativos do receptor), indução de anergia periférica com deleção de clones autoreativos por bloqueio de vias coestimulatórias e tolerização de linfócitos B a autoantígenos do doador por meio do quimerismo hematopoético ${ }^{(61)}$.

Paralelamente aos protocolos clínicos, estamos também desenvolvendo, no Centro de Terapia Celular do Hemocentro de Ribeirão Preto, SP, estudos de seguimento da reconstituição imunológica, da reatividade auto-imune e da expressão gênica das CTH pós-transplante, para investigar o mecanismo da ação terapêutica do TCTH nas DAI ${ }^{(62)}$.

Em relação às outras questões não resolvidas do TCTH para DAI (n.os 2 a 4), levantadas na Tabela 2, há poucas informações científicas disponíveis: 2) Quais são os melhores esquemas de mobilização e de condicionamento? Apenas dois estudos controlados abordaram esta questão, na AR. No primeiro deles, foram comparadas as doses de 5 e $10 \mu \mathrm{g} / \mathrm{kg} / \mathrm{d}$ de G-CSF, isoladamente, para mobilização de CTH. A dose maior de G-CSF foi associada com maior frequiência de reativação da AR, mas foi escolhida para futuros estudos em razão de sua maior eficiência ${ }^{(63)}$. Um outro estudo comparou doses de 100 e $200 \mathrm{mg} / \mathrm{kg}$ de ciclofosfamida, também isoladamente, para o condicionamento de pacientes submetidos a TCTH não manipulado. A dose maior de CY foi associada com um maior período de neutropenia (7 vs. 11 dias) e menor nadir de contagem de plaquetas (16 vs. $143 \times 10^{3} / \mu \mathrm{l}$ ), mas também foi esco- lhida para futuros estudos porque induziu uma resposta clínica mais prolongada do que nos pacientes condicionados com $100 \mathrm{mg} / \mathrm{kg}$ de CY (17-19 vs. 2-3 meses) ${ }^{(64)}$. Em estudos retrospectivos, a mobilização com G-CSF isoladamente foi menos tóxica do que a combinada com ciclofosfamida (que causou mortalidade em 2,6\% dos pacientes), mas induziu maior número de reativações da doença de base ${ }^{(65)}$ e regimes de condicionamento mais agressivos causaram menos recaídas pós-transplante, mas maior mortalidade ${ }^{(11)}$. Assim, a tendência atual é utilizar mobilização com ciclofosfamida em dose baixa ( $2 \mathrm{~g} / \mathrm{m}^{2}$ combinada a G-CSF) e regimes de condicionamento de intensidade reduzida, subablativos, tanto nos transplantes autólogos como nos alogênicos, evitando-se o emprego de irradiação corporal total e esquemas poliquimioterápicos mieloablativos ${ }^{(6,67)}$. 3) Manipulação in vitro ou in vivo do enxerto é necessária para o efeito terapêutico? Um estudo recente com 33 pacientes mostrou que a seleção in vitro de CTH não ofereceu vantagens em relação aos transplantes não-manipulados, ao contrário, esses resultaram em maior frequiência ( 53 vs. 28\%) e duração (201 vs. 154 dias) de resposta clínica, embora essas diferenças não tenham alcançado significância estatística ${ }^{(68)}$. A tendência atual, nos protocolos recém-lançados em países desenvolvidos, é a de usar apenas a manipulação in vivo do enxerto, por exemplo, com anticorpos monoclonais ou policlonais para promover a depleção de linfócitos auto-reativos no sistema linfóide do paciente, sem fazê-lo in vitro. 4) Que adaptações serão necessárias nos países em desenvolvimento para o uso de TCTH em DAI? Por motivos óbvios, esta questão praticamente não é debatida na literatura internacional, mas tem importância vital para a implementação desta terapêutica em países emergentes como o nosso ${ }^{(14-16)}$. A insuficiência de leitos para transplante deverá ser enfrentada com a criação de unidades próprias de terapia celular ou imunoterapia para DAI, como estamos fazendo no HCFMRP, a falta de insumos importantes, como o anticorpo monoclonal anti-CD52 (CAMPATH) ou as colunas de purificação de CTH deverá ser superada com o emprego de estratégias alternativas (anticorpos policlonais antilinfocitários disponíveis no mercado para depleção in vivo de células $\mathrm{T}$, dispensando a manipulação do enxerto in vitro) e, finalmente, a relutância dos especialistas em encaminharem pacientes e do sistema público de saúde em financiar os transplantes só poderá ser vencida com a demonstração, em estudos prospectivos randomizados, de que o TCTH é mais vantajoso, clínica e economicamente, do que as melhores terapias disponíveis para as DAI. Esses estudos, preferentemente, deverão ser realizados em nossa realidade 
particular e não esperar os desenvolvidos em países do Primeiro Mundo.

Em conclusão, a aplicação do transplante de CTH ao tratamento das DAI representa uma promissora alternativa terapêutica a um grupo de doenças de grande importância médico-social. Com todas as dificuldades da nossa realidade, a Medicina brasileira alcançou resultados significativos nesta área, 1) realizando um dos primeiros transplantes no mundo para DAI isolada $\left.{ }^{(2)}, 2\right)$ realizando o primeiro transplante no mundo para uma vasculite de grandes $\operatorname{vasos}^{(18)}$, 3) desenvolvendo o primeiro protocolo mundial de TCTH para diabetes melito do tipo $\mathrm{I}^{(69)}$, alcançando independência insulínica duradoura na maioria dos pacientes, 4) aliviando o sofrimento de dezenas de pacientes intratáveis por meios tradicionais, portadores de doenças reumáticas (Tabela 1), esclerose múltipla ou outras DAI ${ }^{(21)}$. Esses benefícios serão, certamente,

\section{REFERÊNCIAS}

1. Voltarelli JC, Stracieri ABPL, Oliveira MCB, et al: Transplante de células-tronco hematopoéticas em doenças reumáticas - Parte 1: Experiência Internacional. Rev Bras Reumatol 45: 229-41, 2005.

2. Ferreira E, Ribeiro A, Bacal NS, et al: Transplante de células tronco periféricas autólogas no tratamento de doença auto-imune: remissão completa da anemia hemolítica por aglutinina a frio e concomitante vasculite. Boletim da Sociedade Brasileira de Hematologia e Hemoterapia 18 (supl): 191-O, 1996.

3. Marmont AM: New horizons in the treatment of autoimmune disease: Immunoablation and stem cell transplantation. Ann Rev Med 51: 115-34, 2000.

4. Moore J, Tyndall A, Brooks P: Stem cells in the aetiopathogenesis and therapy of rheumatic diseases. Best Practice Res Clin Rheumatol 15: 711-26, 2001.

5. Bingham SH, Snowden J, Morgan G, et al: High dose immunosuppressive therapy and stem cell transplantation in autoimmune and inflammatory diseases. Int Immunopharmacol 2: 399-414, 2002.

6. Gratwohl A, Passweg J, Gerber I, Tyndall A: Stem cell transplantation for autoimmune diseases. Best Practice Res Clin Haematol 14: 755-76, 2002.

7. Burt RK, Slavin S, Burns WH, Marmont A: Induction of tolerance in autoimmune diseases by hematopoietic stem cell transplantation: Getting closer to a cure? Blood 99: 768-84, 2002.

8. Furst DE: Stem cell transplantation for autoimmune disease: progress and problems. Curr Opin Rheumatol 14: 220-4, 2002.

9. Popat U, Krance R: Haematopoietic stem cell transplantation for autoimmune disorders: the American perspective. Br J Haematol 126: 637-49, 2004.

10. Hough RE, Snowden JA, Wulfraat NM: Haematopoietic stem cell transplantation in autoimmune diseases: a European perspective. $\mathrm{Br}$ J Haematol 128: 431-59, 2004.

11. Gratwohl A, Passweg J, Bocelli-Tyndall C, et al: Autologous hematopoietic stem cell transplantation for autoimmune diseases. Bone Marrow Transplant 35: 869-79, 2005. multiplicados muitas vezes quando os principais problemas médico-biológicos do procedimento forem resolvidos (vide acima), melhorando sua relação custo/benefício e permitindo sua aplicação, em larga escala, a pacientes em fase inicial da doença, como ocorre, por exemplo, com as doenças autoimunes da medula óssea, como a anemia aplástica adquirida.

\section{AGRADECIMENTOS}

Às Equipes Multidisciplinares das Unidade de TMO do HCFMRP-USP, HSL-SP, HCFMUSP-SP, RHP-Recife-PE e HIAE-SP pelo cuidado excepcional dedicado aos pacientes, aos especialistas que encaminharam seus pacientes para serem selecionados para o protocolo de transplante e à FAPESP, CNPq, FINEP, FUNDHERP-Hemocentro-RP e FAEPA-HCFMRP-USP pelo apoio financeiro.

12. Tyndall A, Saccardi R: Hematopoietic stem cell transplantation in the treatment of severe autoimmune disease: results from phase I/II studies, prospective randomized trials and future directions. Clin Exp Immunol 141: 1-9, 2005.

13. De Buys P, Khana D, Furst DE: Hemopoietic stem cell transplantation in rheumatic diseases- an update. Autoimmunity Rev 4: 442-9, 2005.

14. Voltarelli JC: Hematopoietic stem cell transplantation for autoimmune diseases in Brazil: Current status and future prospectives. Rev Bras Hematol Hemoter 24: 206-11, 2002.

15. Voltarelli JC: Transplante de células tronco hematopoéticas para doenças auto-imunes no Brasil. Rev Bras Hematol Hemoter 24: 9-13, 2002.

16. Voltarelli JC, Ouyang J: Hematopoietic stem cell transplantation for autoimmune diseases in developing countries: Current status and future prospectives. Bone Marrow Transplant 32: S69-71, 2003.

17. Von Mühlen CA, Hinterholz EL, Garicochea B, et al: Immunosuppression with cyclophosphamide and fludarabine, with support of autologous CD34+ stem cells, in the treatment of severe scleroderma. Rev Bras Reumatol 44: 169-174, 2004.

18. Voltarelli JC, Oliveira MCB, Stracieri ABPL, et al: Haematopoietic stem cell transplantation for refractory Takayasus's arteritis. Rheumatology 43: 1308-9, 2004.

19. Burt RK, Oyama Y, Traynor A, et al: Hematopoietic stem cell transplantation for systemic sclerosis with rapid improvement in skin scores: is neoangiogenesis occurring? Bone Marrow Transplantation 32: 565-7, 2003.

20. Fiehn C, Hensel M: High dose chemotherapy with haematopoietic stem cell transplantation in primary systemic vasculitis, Behçet's diseases and Sjogren's syndrome. In "Stem cell therapy for autoimmune diseases", edited by RK Burt \& A Marmont, Landes Bioscience, Georgetown, TX, USA, 411-418, 2004.

21. Voltarelli JC, Stracieri AB, Rodrigues MC, et al: Outcome fo autologous HSCT for severe and refractory autoimmune diseases in Brazil. Bone Marrow Transplantation 33 (Suppl 1): S145, 2004.

22. Voltarelli JC, Stracieri ABPL, Oliveira MCB, et al: Transplante autólogo de células tronco hematopoéticas para nefrite lúpica: Resultados brasileiros iniciais. J Bras Nefrol 25: 65-72, 2003. 
23. Rosen O, Massenkeil G, Hiepe F, et al: Cardiac death after autologous stem cell transplantation (ASCT) for treatment of systemic sclerosis (SSC): no evidence for cyclophosphamide-induced cardiomyopathy. Bone Marrow Transplant 58: 314-7, 2003.

24. Houssiau FA: Management of refractory systemic rheumatic diseases. Acta Clin Belg 58: 314-7, 2003.

25. Voltarelli JC: Autologous hematopoietic stem cell transplantation in type I diabetes mellitus. Rev Bras Hematol Hemoter 26: 43-5, 2004.

26. Voltarelli JC, Donadi EA, Martinez JAB, Vianna EO, Sarti W: Bronchial asthma and idiopathic pulmonary fibrosis as potential targets for hematopoietic stem cell transplantation. In "Stem cell therapy for autoimmune diseases", edited by RK Burt \& A Marmont, Landes Bioscience, Georgetown, TX, USA, p. 457-67, 2004.

27. Voltarelli JC: Perspectivas de terapia celular na esclerose lateral amiotrófica. Rev Bras Hematol Hemoter 26: 155-6, 2004.

28. Thomas ED: Pros and cons of stem cell transplantation for autoimmune diseases. J. Rheumatol 24 (Supl 48): 100-2, 1997.

29. Potter M, Black C, Berger A: Bone marrow transplantation for autoimmune diseases: An interesting approach- but only for patients with few alternatives. Br Med J 318: 750-1, 1999.

30. Snowden JA, Nivison-Smith I, Biggs JC, et al: Risk taking in patients with rheumatoid arthritis: are the risks of hematopoietic stem cell transplantation acceptable? Rheumatology 38: 321-4, 1999.

31. Laxer RM, Harrison C: Bioethical issues in autologous stem cell transplantation in children and adults with arthritis. J Rheumatol 28: 2147-9, 2001.

32. McKendry RJ, Coyle D: Treatment related mortality versus quality of life- A balancing act. J Rheumatol 28: 688-90, 2001.

33. Stosor V, Zembower TR: Infection in the hematopoietic stem cell transplant recipient with autoimmune disease. In "Stem Cell Therapy for Autoimmune Diseases", ed. By RK Burt \& AM Marmont, Landes Bioscience, p. 261-75, 2004.

34. Crippa F, Golmberg L, Carter RA, et al: Infectious complications after autologous CD34-selected peripheral blood stem cell transplantation. Biol Blood Marrow Transplant 8: 281-9, 2002.

35. Nash RA, Dansey R, Storek J, et al: Epstein-Barr virus-associated posttransplantation lymphoproliferative disorder after high-dose immunosuppressive therapy and autologous CD34-selected hematopoietic stem cell transplantation for severe autoimmune diseases. Biol Blood Marrow Transplant 9: 583-91, 2003.

36. Barron KS, Wallace C (eds): Autologous stem cell transplantation for pediatric rheumatic diseases. J Rheumatol 28: 2337-58, 2001.

37. Martin DK, Singer PA: Bone marrow transplant for rheumatoid arthritis: The costs of a cure. J, Rheumatol 26: 1217-8, 1999.

38. Jian O-Y, Bing C, Cuiping Y: A pilot study in treatment of severe SLE relapsing after ABMT by purified peripheral blood CD $34^{+}$cells transplantation in China. Bone Marrow Transplant 31 (Suppl 1): S99, 2003

39. Zhao J, Fu Y, Peng X: Autologous hematopoietic stem cell transplantation in the treatment of systemic lupus erythematosus. Bone Marrow Transplant 29 (Suppl 2): S15, 2002.

40. Chen J, Gu L-J, Xue H-L, et al: Primary report on the application of CD34+ autologous peripheral blood progenitor cell transplantation in the treatment of children with refractory systematic lupus erythematosus (SLE). Blood (Supl 1): 475b, 2002.

41. Lee T-L, Chan GC, Há S-Y, et al: Autologous stem cell transplant in 3 patients with refractory autoimmune diseases. Blood 102: 484-5b, 2004.
42. Lisukov IA, Sizikova AS, Kulagin AD, et al: High dose immunosuppression with autologous stem cell transplantation in severe refractory systemic lupus erythematosus. Lupus 13: 89-94, 2004.

43. Nagy K, Vertesi G, Marton G, Lombay B, et al: Allogenic HLA identical bone marrow transplantation in patient with juvenile idiopathic/chronic/arthritis/JIA. Bone Marrow Transplantation 33 (Suppl 1): S 146, 2004.

44. Choi J-H, Ahn M-J, Oh H-S, et al: Autologous peripheral blood stem cell transplantation in refractory autoimmune diseases. Blood 102: 484b, 2004

45. Fassas A, Anagnostopoulos A, Kazis A, et al: Peripheral blood stem cell transplantation in the treatment of progressive multiple sclerosis: first results of a pilot trial. Bone Marrow Transplant 20: 631-8, 1997.

46. Kozak T, Havrdava E, Pitha J: High dose immunosuppressive therapy with PBPC support in the treatment of poor risk multiple sclerosis. Bone Marrow Transplant 25: 525-31, 2000.

47. Muraro PA, Martin R: Immunological questions on hematopoietic stem cell transplantation for multiple sclerosis. Bone Marrow Transplant 32 (Suppl 1): S41-S44, 2003.

48. Petri M, Jones RJ, Brodsky RA: High-dose cyclophosphamide without stem cell transplantation in systemic lupus erythematosus. Arthritis Rheum 48: 166-73, 2003.

49. Drachman D, Brodsky R: High-dose cyclophosphamide for autoimmune neurologic disease. Curr Opin Oncol 17: 83-8, 2005.

50. Moyo VM, Smith D, Brodsky I, et al: High-dose cyclophosphamide for refractory autoimmune haemolytic anemia. Blood 100: 704-6, 2002.

51. Traynor AE, Schroeder J, Rosa RM, et al: Treatment of severe systemic lupus erythematosus with high-dose chemotherapy and hematopoietic stem cell-transplantation: a phase I study. Lancet 356: 701-7, 2000.

52. Durez P, Toungouz M, Schandené L, et al: Remission and immune reconstitution after $\mathrm{T}$-cell depleted stem-cell transplantation for rheumatoid arthritis. Lancet 352: 881, 1998.

53. Verburg RJ, Kruize AA, Van den Hoogen FHJ, et al: High-dose chemotherapy and autologous hematopoietic stem cell transplantation in patients with rheumatoid arthritis. Arthritis \& Rheumatism 44: 754-60, 2001.

54. Brinkman DMC, Ten Cate R, Vossen JM: Decrease in synovial cellularity and cytokine expression after autologous stem cell transplantation in patients with juvenile idiopathic arthritis. Arthritis Rheum 46: 1121-4, 2002.

55. Ponchel F, Verburg RJ, Bingham SJ, et al: Interleukin-7 deficiency in rheumatoid arthritis: consequences for therapy-induced lymphopenia. Arthritis Res Ther 7: R80-R92, 2005.

56. Thiel A, Alexander T, Schmidt CA, et al: Immune reconstitution after hematopoietic stem cell transplantation. In "Stem cell therapy for autoimmune diseases", edited by RK Burt \& A Marmont, Landes Bioscience, Georgetown, TX, USA, p 206-222, 2004.

57. De Kleer IM, Brinkman DMC, Ferster A, et al: Autologous stem cell transplantation for refractory juvenile idiopathic arthritis: Analysis of clinical effects, mortality, and transplant related mortality. Ann Rheum Dis 63: 1318-26, 2004.

58. Muraro P, Douek DC, Packer A, et al: Thymic output generates a new and diverse TCR repertoire after autologous stem cell transplantation in multiple sclerosis patients. J Exp Med 201: 805-16, 2005 . 
59. Burt RK, Traynor AE, Oyama Y, Barr WG: Plasticity of hematopoietic stem cells: enough to induce tolerance and repair tissue? Arthritis Rheum 4: 855-8, 2002.

60. Hacein-Bey-Abina S, Von Kalle C, Schmidt M, et al: A serious adverse event after successful gene therapy for $\mathrm{X}$-linked severe combined immunodeficiency. New Engl J Med 348: 255-6, 2003.

61. Sykes M, Nikolic B: Treatment of severe autoimmune disease by stem cell transplantation. Nature 435: 620-7, 2005.

62. Farias KCRM, Oliveira MCB, Godoi DF, et al: Immune reconstitution and cytokine profile following autologous hematopoietic stem cell transplantation for autoimmune diseases. XXIX Meeting of the Brazilian Society for Immunology, Abstract TIG-9, p. 157, 2004.

63. Snowden JA, Biggs JC, Milliken ST, et al: A randomised, blinded, placebo-controlled, dose scalation study of the tolerability and efficacy of filgrastrim for haematopoietic stem cell mobilisation in patients with severe active rheumatoid arthritis. Bone Marrow Transplant 22: 1035-41, 1998.

64. Snowden JA, Biggs JC, Milliken ST, et al: A phase I/II dose escalation study of intensified cyclophosphamide and autologous blood stem cell rescue in severe, active rheumatoid arthritis. Arthritis Rheum 42: 2286-92, 1999.

65. Burt RK, Fassas A, Snowden J, et al: Collection of hematopoietic stem cells from patients with autoimmune diseases. Bone Marrow Transplant 28: 1-12, 2001.

66. Burt RK, Kallunian K, Patel D, et al: The rationale behind autologous autoimmune hematopoietic stem cell transplant conditioning regimens : concerns over the use of total-body irradiation in systemic sclerosis. Bone Marrow Transplant 34: 745-51, 2004.

67. Burt RK, Cohen B, Rose J, et al: Hematopoietic stem cell transplantation for multiple sclerosis. Arch Neurol 62: 860-4, 2005.

68. Moore J, Brooks P, Milliken S, et al: A pilot randomized trial comparing CD34-selected versus unmanipulated hemopoietic stem cell transplantation for severe, refractory rheumatoid arthritis. Arthritis Rheum 46: 2301-9, 2002.

69. Voltarelli JC, Couri CEB, Oliveira MC, et al: Autologous hematopoietic stem cell transplantation for type I diabetes mellitus. Blood 104: 391b, 2004. 